\title{
The effects of feeding more milk on periprandial plasma glucagon- like peptide-2 concentrations in preweaning dairy calves
}

\author{
J. Haisan, ${ }^{*}$ M. Oba, ${ }^{*}$ and T. Suginot ${ }^{1}$ \\ *Department of Agricultural, Food and Nutritional Science, University of Alberta, Edmonton, T6G 2P5, Canada \\ †The Research Center for Animal Science, Graduate School of Biosphere Science, Hiroshima University, Higashi-Hiroshima, Japan 739-8528
}

\begin{abstract}
The objective of this study was to evaluate periprandial plasma concentrations of glucagon-like peptide-2 (GLP-2), glucose, and $\beta$-hydroxybutyrate (BHB) in response to a milk meal in preweaning dairy calves. Nineteen Holstein heifer calves were fed either a high $(10 \mathrm{~L} / \mathrm{d} ; \mathrm{n}=9)$ or low $(5 \mathrm{~L} / \mathrm{d} ; \mathrm{n}=10)$ amount of pasteurized whole milk from d 2 to 50 of life. Calves were housed in individual pens for the first $19 \pm 3 \mathrm{~d}$ and fed only milk before being moved to a group pen, where they remained on their respective milk treatment and offered calf starter ad libitum. Blood samples were collected sequentially for 240 min following their milk meal at wk 3,5 , and 7 of life to characterize the periprandial response in plasma concentrations of GLP-2, glucose, and BHB. Baseline plasma glucose concentrations were increased, when a high amount was fed; however, we found no difference in area under the curve. Feeding a high amount of whole milk had no effect on baseline or periprandial plasma BHB concentrations. Baseline plasma GLP-2 concentrations decreased as calves aged. Feeding a high amount of whole milk tended to significantly increase baseline GLP-2 concentrations throughout compared with calves fed a low amount. The periprandial response of GLP-2 was not biphasic until calves were 7 wk old. In conclusion, feeding a high amount of milk may increase GLP-2 concentrations in preweaning calves, although its exact mechanism is unknown.
\end{abstract}

Key words: calves, periprandial GLP-2, whole milk

\section{INTRODUCTION}

As a member of the glucagon-like peptide family, glucagon-like peptide-2 (GLP-2) has important biological functions within the gastrointestinal tract. Glucagonlike peptide- 2 has been found to increase energy intake

Received May 7, 2018.

Accepted August 17, 2018.

${ }^{1}$ Corresponding author: sugino@hiroshima-u.ac.jp by increasing uptake of luminal nutrients (Kato et al., 1999), and has the ability to enhance gut integrity after injury by protecting intestinal mucosa from inflammation and promoting barrier function (Connor et al., 2013; Kvidera et al., 2017). As exogenous supplementation of GLP-2 in ruminants has shown promise to improve gut health and development (Connor et al., 2013; Kvidera et al., 2017), methods to promote endogenous GLP-2 secretion have gained interest. In nonruminants it is well documented that nutrient supply to the small intestine increases GLP-2 secretion, and some evidence exists with ruminants that this holds true (TaylorEdwards et al., 2010, 2011).

Similarly, Castro et al. (2016) evaluated the effects of feeding an increased amount of milk replacer to young calves and found that increasing the amount of milk replacer fed increased GLP-2 concentrations within the first few weeks of life. In older calves, supplementing calf starter with butyrate has been associated with increased plasma GLP-2 concentrations (Gorka et al., 2009). However, to our knowledge, the effect of feeding an increased amount of whole milk on GLP-2 concentrations throughout the preweaning period, and the response in periprandial concentrations to the milk meal, has not been evaluated. Therefore, the objective of our study was to evaluate the periprandial response of GLP-2, glucose, and BHB concentrations in plasma to a milk meal throughout the preweaning period. Given that feeding more milk increases nutrient supply, we expected that feeding a higher rate of milk would increase plasma GLP-2 concentration.

\section{MATERIALS AND METHODS}

All procedures were pre-approved by the Animal Care and Use Committee for Livestock at the University of Alberta (AUP \#1553).

\section{Experimental Design and Feeding Regimen}

Twenty female Holstein calves were fed 2 L of reconstituted powdered colostrum (HeadStart, Saskatoon Colostrum Company Ltd., Saskatoon, SK, Canada) 
delivering $120 \mathrm{~g}$ of $\mathrm{IgG}$ within $6 \mathrm{~h}$ of life followed by 3 meals of pooled, pasteurized colostrum $(2 \mathrm{~L}$ each, approximately $12 \mathrm{~h}$ apart) during the first $2 \mathrm{~d}$ after birth. On d 2 of life, calves were balanced for birth BW and randomly assigned to 1 of 2 feeding rates: high $(10 \mathrm{~L} / \mathrm{d}$; $\mathrm{n}=10)$ or low $(5 \mathrm{~L} / \mathrm{d} ; \mathrm{n}=10)$ pasteurized whole milk. One calf weaned herself from milk before wk 3 and was removed from the study; therefore, final numbers were $\mathrm{n}=9$ for high and $\mathrm{n}=10$ for low. All calves were allowed $2.5 \mathrm{~L}$ of pasteurized whole milk $(5.34 \mathrm{Mcal} / \mathrm{kg}$; calculated as per NRC, 2001; pasteurized at $60^{\circ} \mathrm{C}$ for 60 min) per feeding. Calves were offered their respective milk treatment for $50 \mathrm{~d}$ before a 10 -d weaning transition began, where offered milk was reduced by $10 \%$ per day such that all calves were weaned at $60 \mathrm{~d}$. Calves were housed in individual pens and offered milk using the Calf Rail (Foester-Technik, Engen, Germany) feeding system for the first $19 \pm 3 \mathrm{~d}$ of life, after which calves were moved to a group pen and fed using an automated calf feeder (CF1000+, DeLaval Canada, ON, Canada). Calf feeding start times while on both systems were 0600, 1100, 1600, and $2200 \mathrm{~h}$ for high, and 0600 and $1600 \mathrm{~h}$ for low. If calves missed a feeding, the meal was skipped and intake was not made up later in the day; daily milk intake was recorded automatically. Calf starter (Advantage 4 Dairy Calf Starter Plus, HiPro Feeds, Olds, AB, Canada; 20\% CP) was provided ad libitum once calves were moved to the group pen at 19 $\pm 3 \mathrm{~d}$, and its intake was recorded automatically using BioControl bunks (BioControl, Rakkestad, Norway) that identified calves by their radio frequency identification tag and recorded feed disappearance from the bunks. Water was provided throughout the study.

\section{Sample Collection}

At $19 \pm 3$ (wk 3; before calves were moved to the group pen), $33 \pm 3$ (wk 5), and $47 \pm 3 \mathrm{~d}$ (wk 7), a jugular catheter was placed and a 5 -mL blood sample was collected into tubes containing sodium heparin (BD Vacutainer, Franklin Lakes, NJ) at 0, 10, 20, 30, $45,60,90,120,150,180,210$, and $240 \mathrm{~min}$ relative to the morning milk meal for both treatment groups. Following collection, blood samples were immediately treated with $2.5 \mu \mathrm{L}$ of aprotinin $(0.01 \mathrm{mg} / \mu \mathrm{L}$ of CAS: 9087-70-1, Sigma-Aldrich, St. Louis, MO) and placed on ice before centrifugation at $3,000 \times g$ for $20 \mathrm{~min}$ at $4^{\circ} \mathrm{C}$; harvested plasma samples were stored at $-20^{\circ} \mathrm{C}$ until analysis. All sampling occurred a minimum of 6 $\mathrm{h}$ after the last milk meal; however, calves were not fasted from starter before sampling on wk 5 and 7 . Body weight was measured on wk 3,5 , and 7 before the morning meal.

\section{Sample Analysis}

Plasma samples were analyzed for GLP-2, glucose, and BHB. Plasma GLP-2 concentration was analyzed using time-resolved fluoroimmunoassay techniques as described by Sugino et al. (2004), Elsabagh et al. (2017), and Inabu et al. (2017). Briefly, GLP-2 concentrations were measured using a solid-phase competition immunoassay with Eu-labeled human GLP-2 (Peptide Institute Inc., Osaka, Japan), polyclonal anti-rat GLP2 (Yanaihara Institute Inc., Shizuoka, Japan), and polystyrene microtiter strips coated with goat-antirabbit $\gamma$-globulin (Elsabagh et al., 2017). The intraand interassay coefficients of variation were 2.7 and $2.2 \%$, respectively. Plasma glucose concentration was determined using a glucose oxidase/peroxidase enzyme dianisidine dihydrochloride (Sigma-Aldrich), and absorbance at $450 \mathrm{~nm}$ was determined using a SpectraMax 190 plate reader (Molecular Devices Corp., Sunnyvale, $\mathrm{CA}$ ). We determined BHB after oxidation of BHB to acetoacetate using 3-hydroxybutyrate dehydrogenase (Roche, Mississauga, ON, Canada) and measuring the reduction of $\mathrm{NAD}^{+}$to NADH using a SpectraMax 190 plate reader at $340 \mathrm{~nm}$.

\section{Calculations and Statistical Analysis}

Area under the curve (AUC) for plasma GLP-2 concentrations was calculated from the raw data in Excel 2010 (Microsoft Corp., Redmond, WA) using the trapezoid rule with the equation $\mathrm{AUC}=$ (concentration $\mathrm{A}+$ concentration $\mathrm{B}) / 2 \times($ time $\mathrm{B}$ - time $\mathrm{A})$. The area between each time point was calculated and then added together to get total AUC for the entire sampling period.

Statistical analyses were conducted using the FIT model of JMP (version 13; SAS Institute Inc., Cary, $\mathrm{NC}$ ) according to equation 1 to determine overall treatment effects with week as a repeated measure. For sequential blood sampling, treatment effects on plasma GLP-2 and metabolite concentrations were evaluated separately for each week with time relative to a milk meal as a repeated measure:

$$
Y_{i j}=\mu+T_{i}+S_{j}+T_{i j}+e_{i j},
$$

where $Y_{i j}$ is the dependent variable, $\mu$ is the overall mean, $T_{i}$ is the fixed effect of treatment, $S_{j}$ is the fixed effect of week or time used as a repeated measure, $\mathrm{TS}_{\mathrm{ij}}$ is the effect of treatment by time, and $\mathrm{e}_{\mathrm{ij}}$ is the residual. Significance was declared when $P<0.05$ and tendencies were discussed when $P<0.10$. 
Table 1. The effect of feeding a high $(10 \mathrm{~L} / \mathrm{d} ; \mathrm{n}=9)$ or low $(5 \mathrm{~L} / \mathrm{d} ; \mathrm{n}=10)$ amount of milk preweaning on weekly milk, calf starter, total ME intake, and BW of calves

\begin{tabular}{|c|c|c|c|c|c|c|c|c|c|c|}
\hline \multirow[b]{2}{*}{ Variable } & \multicolumn{2}{|c|}{ Week 3} & \multicolumn{2}{|c|}{ Week 5} & \multicolumn{2}{|c|}{ Week 7} & \multirow[b]{2}{*}{$\mathrm{SE}$} & \multicolumn{3}{|c|}{$P$-value for fixed effect ${ }^{1}$} \\
\hline & Low & High & Low & High & Low & High & & Trt & Week & Trt $\times$ week \\
\hline ME intake, Mcal/d & $2.19^{\mathrm{d}}$ & $4.10^{\mathrm{ab}}$ & $2.94^{\mathrm{c}}$ & $4.26^{\mathrm{ab}}$ & $4.00^{\mathrm{b}}$ & $4.67^{\mathrm{a}}$ & 0.215 & $<0.001$ & $<0.001$ & 0.03 \\
\hline $\mathrm{BW},{ }^{2} \mathrm{~kg}$ & 44.9 & 51.4 & 52.1 & 61.0 & 61.6 & 71.6 & 1.59 & 0.003 & $<0.001$ & 0.59 \\
\hline
\end{tabular}

${ }^{\mathrm{a}-\mathrm{d}}$ Main effects within a row with different superscripts differ $(P<0.05)$.

${ }^{1}$ Trt $=$ treatment.

${ }^{2}$ All weeks significantly different from each other.

\section{RESULTS}

Due to treatment, milk intake was greater for high amounts of milk by d 6 of life and remained greater until weaning $(P<0.001$; Table 1$)$. We found no difference in weekly average starter intake at wk 5 between high and low amounts of milk; however, at wk 7 starter intake was higher for low than high amounts of milk (773 vs $292 \mathrm{~g} / \mathrm{d} ; P=0.001$ ). As such, calves receiving high amounts of milk had greater ME intake on wk 3 $(4.1$ vs. $2.2 \mathrm{Mcal} / \mathrm{d} ; P<0.001), 5(4.3$ vs. $2.9 \mathrm{Mcal} / \mathrm{d}$; $P<0.001)$, and 7 (4.7 vs. $4.0 \mathrm{Mcal} / \mathrm{d} ; P=0.003)$.

Average birth BW did not differ between treatments (36.1 vs. $37.3 \pm 1.13 \mathrm{~kg} / \mathrm{d}$ for high and low, respectively; $P=0.47$ ). Average daily gain of calves fed a high amount of milk was greater compared with a low amount for the first $3 \mathrm{wk}$ of life $(0.73$ vs. $0.34 \mathrm{~kg} / \mathrm{d} ; P$ $=0.002)$, which resulted in calves fed high amounts having an increased BW at wk 3, 5, and 7 .

Periprandial plasma concentrations of GLP-2 tended to be higher for calves fed high compared with low amounts of milk at wk 3 (Figure 1a) and 5 (Figure 1b), and baseline GLP-2 concentrations tended to be higher for calves fed high compared with low amounts of milk throughout (Table 2). In addition, AUC was greater when high amounts were fed as compared with low. Overall, we found a decrease in baseline GLP-2 concentrations as calves aged as well as a change in the response to a meal over time. At wk 3, GLP-2 concentrations decreased following a meal $(P<0.01)$, with no biphasic response. The lack of biphasic response continued at wk 5, but GLP-2 concentrations increased following a meal in a biphasic manner at wk 7 (Figure 1c).

Plasma glucose concentrations were higher when a high amount of milk was fed regardless of calf age; however, we observed no difference in periprandial glucose response to a meal between treatments. We noted no difference in baseline or periprandial responses in BHB concentrations between treatments regardless of calf age (Table 2).

\section{DISCUSSION}

In the present study, plasma GLP-2 concentrations were measured in dairy calves fed either a high or low amount of milk to determine how plane of nutrition affects GLP-2 concentration during the preweaning period. It is well documented that GLP-2 secretion is enhanced through increasing nutrient supply (Burrin et al., 2001; Rowland and Brubaker, 2011), and in the current study feeding a high amount of milk tended to increase baseline GLP-2 concentrations at wk 3 and 5, which is in alignment with current theories regarding nutrient stimulation of GLP-2 (Taylor-Edwards et al., 2010).

Baseline glucose concentrations were greater when a high amount was fed. These findings were expected, as calves fed the high amount of milk consumed 1.9, 1.8, and 1.8 times the amount of milk as calves fed the low amount at wk 3, 5, and 7, respectively, which would have resulted in increased lactose consumption, which has been shown to increase blood glucose concentrations (Palmquist et al., 1992). However, we found no relationship between baseline GLP-2 concentrations and baseline glucose concentrations $(\mathrm{r}=0.16)$ or total AUC for glucose $(r=0.03)$. Our findings (Table 3) are supported by Castro et al. (2016), who evaluated the effects of glucose on GLP-2 and found them to be nonstimulatory. We expected a difference in BHB concentrations between calves fed high and low amounts of milk, as BHB has been shown to be an indicator of rumen fermentation (Khan et al., 2016), increasing with starter intake; however, this was not the case in the current study. We noted no correlation between starter intake and premeal BHB $(\mathrm{r}=0.24)$, no difference in BHB between treatments at any measured time points, and no association between baseline BHB and baseline GLP-2 concentrations $(\mathrm{r}=-0.13)$ or total AUC for GLP-2 $(\mathrm{r}=-0.18)$.

As mentioned, because nutrient supply to the intestinal lumen is a primary stimulant for GLP-2 secretion, one would expect starter intake to play a large role 

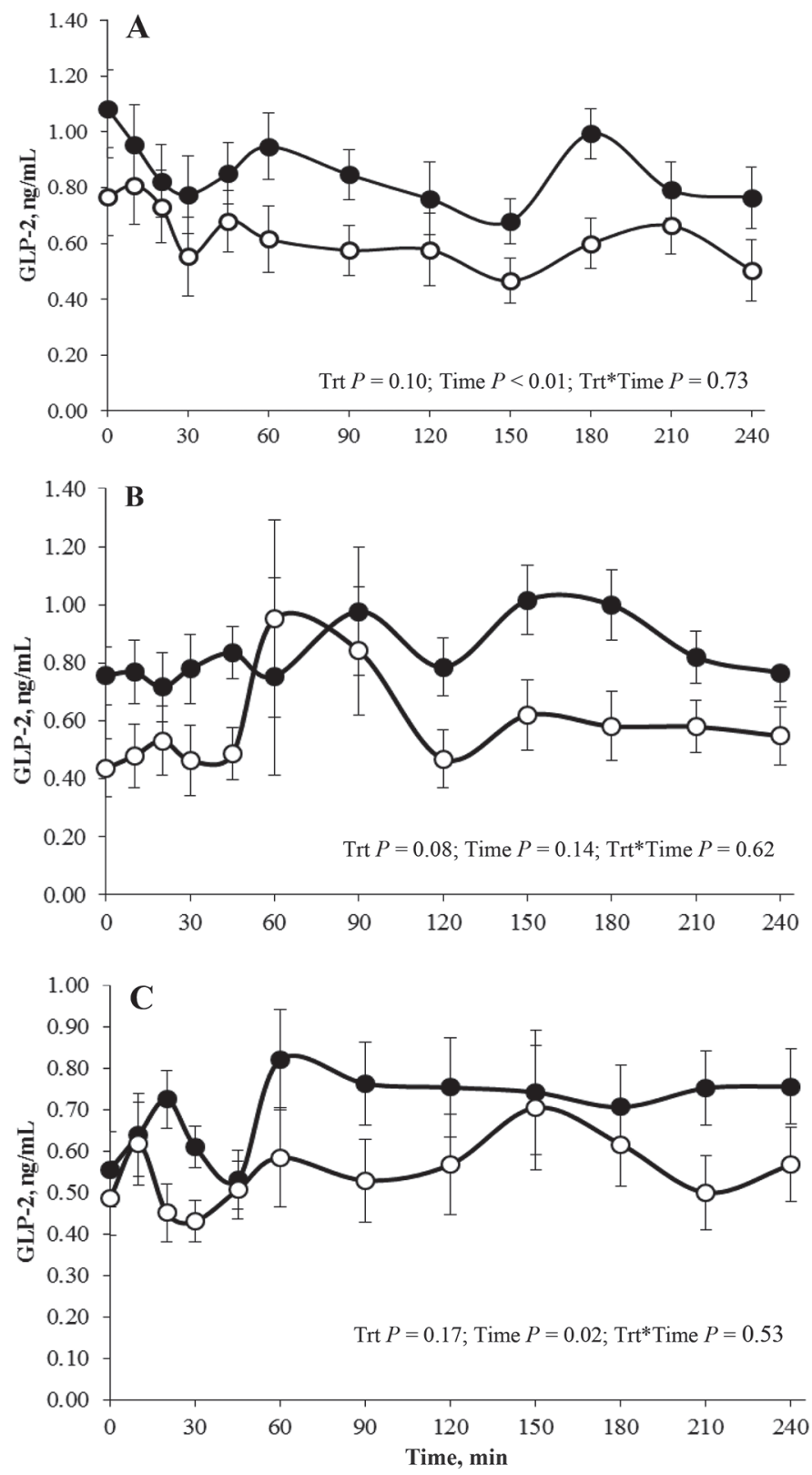

Figure 1. Periprandial glucagon-like peptide-2 (GLP-2) concentrations in response to a milk meal when calves were fed a high $(10 \mathrm{~L} / \mathrm{d} ; \mathrm{n}$ $=9$; solid circle) or low $(5 \mathrm{~L} / \mathrm{d} ; \mathrm{n}=10$; open circle) amount of milk at wk $3(\mathrm{~A}), 5(\mathrm{~B})$, and 7 (C). Trt = treatment. Error bars denote SEM.

in GLP-2 secretion of a preweaning calf for 2 reasons. First, the upper gastrointestinal tract is unable to digest starter to its maximum capacity preweaning, thus more undigested nutrient reach the small intestine. Second, butyrate is an end-product of starter fermentation in the rumen, and previous studies have reported that VFA, primarily butyrate, can stimulate GLP-2 secretion in ruminants (Gorka et al., 2009; Elsabagh et al.,
2017). Therefore, we expected GLP-2 concentrations to increase with increased starter intake; however, in the current study, regardless of dietary treatment or week of life, we found no correlation between starter intake and baseline GLP-2 concentrations (Table 3).

In our study, baseline plasma GLP-2 concentrations decreased with age, similar to Inabu et al. (2017) who found GLP-2 concentrations decreased with age in preweaning calves. In swine, it has been found that GLP-2 concentrations are significantly increased in 1-d-old suckling pigs following nutrient intake and GLP-2 is released to a lesser extent as the suckling period persists (Burrin et al., 2003b; Petersen et al., 2003). Evidence also exists indicating differences in the effect of GLP-2 supplementation on fetal and neonatal piglets, likely due to normal developmental changes in the intestines (Petersen et al., 2001).

To the best of our knowledge, the current study is the first of its kind to evaluate the periprandial response of GLP-2 concentrations to a milk meal in preweaning calves as they age. Feeding a high amount of milk tended to increase periprandial GLP-2 concentrations at wk 3 and 5 relative to a low amount, which is likely associated with the fact that baseline GLP-2 concentrations were increased for high amounts at these time points. In addition, although GLP-2 AUC increased when high amounts of milk were fed, GLP-2 AUC was correlated with baseline GLP-2 concentrations ( $\mathrm{r}=$ $0.67, P<0.05)$. Whereas these findings were expected, because despite a difference in total volume of milk consumed per day the meal size was the same between treatments, it is important to note that the amount of milk fed was confounded with feeding frequency, as high calves were fed 4 times per day and low calves 2 times per day. Althouhg several dietary factors affecting nutrient delivery to the small intestine have been investigated in calves (Burgstaller et al., 2017), little work has been conducted mimicking the scenario presented in the current study; therefore, it is difficult to predict the effect of feeding an increased amount of milk while keeping meal size the same on nutrient flow to the small intestine. However, as enteral inflow of nutrients is the primary stimulant for GLP-2 secretion (Burrin et al., 2003a), the increased frequency of feed delivery, resulting in increased frequency of entry of nutrients to the intestine, could act to stimulate GLP-2 regardless of the total amount of milk fed per day.

In the current study it appeared that GLP-2 secretion changed with age, as the responses in periprandial plasma concentrations of GLP-2 to a milk meal differed at each measured time point. At wk 3 periprandial concentrations decreased, at wk 5 remained constant, and at wk 7 increased in a biphasic manner relative 
Table 2. The effect of feeding a high $(10 \mathrm{~L} / \mathrm{d} ; \mathrm{n}=9)$ or low $(5 \mathrm{~L} / \mathrm{d} ; \mathrm{n}=10)$ amount of milk preweaning on baseline plasma glucagon-like peptide-2 (GLP-2) concentrations, area under the curve (AUC), baseline plasma glucose and BHB concentrations, and AUC for glucose and plasma in response to a milk meal

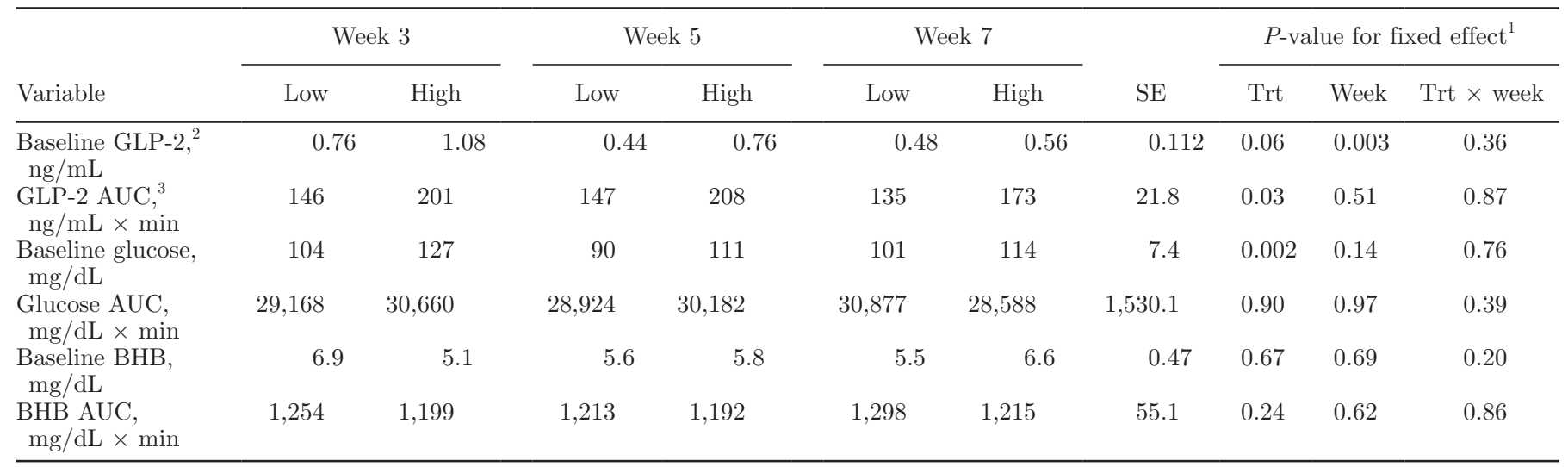

${ }^{1}$ Trt $=$ treatment.

${ }^{2}$ Wk 3 differs from wk 5 and $7(P<0.05)$.

${ }^{3}$ Area under the curve for all variables was calculated as $\mathrm{AUC}=($ concentration $\mathrm{A}+$ concentration $\mathrm{B}) / 2 \times($ time $\mathrm{B}-$ time $\mathrm{A})$.

to a milk meal. It is important to note that, within the current study, amount of milk fed was confounded by starter intake when evaluating GLP-2 concentrations at each time point. Likewise, given the changes in baseline GLP-2 concentrations and the periprandial response to a milk meal as calves age, we speculated that an effect of starter intake and rumen fermentation occurred, as VFA are known to modulate endocrine secretion. For example, when evaluating the effect of VFA on insulin secretion, whereas VFA have been found to be nonstimulatory for insulin release in rodents, butyrate and propionate in circulation stimulate insulin release in ruminants (de Jong, 1982; Croom et al., 1992). Similarly, Matsunaga et al. (1999) evaluated insulin concentrations in sheep following a meal versus with intraruminal infusions of VFA and found that VFA were stimulatory such that the postprandial concentration of VFA could be the physiological signal for insulin secretion. Although it has been found that butyrate acts as a stimulant for GLP-2 release (Gorka et al., 2009; Elsabagh et al., 2017) in ruminants, the effect that postprandial level of VFA has on GLP-2 concentrations have not been evaluated.

Research regarding the role of VFA in endocrine secretion has primarily been conducted with solid feed, which does not entirely explain the results seen in the current study when a milk meal is fed. Nevertheless, as whole milk contains naturally occurring VFA, including butyric acid (Parodi, 1997), it is possible an additive response exists between the VFA present in milk and those present in the digestive tract of the calf that acts to elicit the responses seen in our study.

Much of the information regarding GLP-2 secretion has been inferred from what we know of GLP-1, as both peptides are believed to be secreted in parallel (Burrin et al., 2001). Secretion of GLP-1 and GLP2 has been reported to occur in a biphasic pattern, with an early peak and longer second phase (Brubaker

Table 3. Correlation coefficients between glucagon-like peptide-2 (GLP-2), starter intake, ME intake, plasma glucose, and BHB concentrations when a high $(10 \mathrm{~L} / \mathrm{d} ; \mathrm{n}=9)$ or low $(5 \mathrm{~L} / \mathrm{d} ; \mathrm{n}=10)$ amount of milk was fed to dairy calves preweaning ${ }^{1}$

\begin{tabular}{|c|c|c|c|c|c|c|c|}
\hline Item & $\begin{array}{l}\text { Baseline } \\
\text { GLP-2 }\end{array}$ & $\begin{array}{l}\text { GLP-2 } \\
\text { AUC }\end{array}$ & $\begin{array}{l}\text { Baseline } \\
\text { glucose }\end{array}$ & $\begin{array}{l}\text { Glucose } \\
\text { AUC }\end{array}$ & $\begin{array}{c}\text { Baseline } \\
\text { BHB }\end{array}$ & $\begin{array}{l}\text { BHB } \\
\text { AUC }\end{array}$ & $\begin{array}{c}\text { Starter } \\
\text { intake }\end{array}$ \\
\hline \multicolumn{8}{|l|}{ Baseline GLP-2, ng/mL } \\
\hline Baseline glucose, mg/dL & 0.16 & 0.14 & & & & & \\
\hline Glucose AUC, mg/dL $\times \min$ & 0.03 & -0.03 & $0.44^{*}$ & & & & \\
\hline Baseline BHB, mg/dL & -0.13 & -0.18 & -0.15 & 0.001 & & & \\
\hline $\mathrm{BHB} \mathrm{AUC}, \mathrm{mg} / \mathrm{dL} \times \min$ & 0.02 & 0.01 & 0.20 & 0.05 & $0.33^{*}$ & & \\
\hline
\end{tabular}

${ }^{1}$ Area under the curve (AUC) for all variables was calculated as AUC $=($ concentration $\mathrm{A}+$ concentration $\mathrm{B}) / 2 \times($ time $\mathrm{B}-$ time $\mathrm{A})$. ${ }^{*} P<0.05$. 
and Anini, 2003). The initial release occurs within 30 min of nutrient intake and is likely caused by stimulation of L cells by neural and endocrine factors. When using rodents as a model, strong evidence exists that stimulation of the vagus nerve results in the early peak of GLP-2 (Rocca and Brubaker, 1999; Brubaker and Anini, 2003), whereas the late phase occurs 1 to $2 \mathrm{~h}$ postprandially as a result of direct stimulation of $\mathrm{L}$ cells by nutrients (Xiao et al., 2001; Brubaker and Anini, 2003; Janssen et al., 2013).

Stimulation of the vagus nerve in ruminants can occur through nutrient intake, changes in ruminal $\mathrm{pH}$, and mechanical stimulation (Ash, 1959), and although little literature has been published using ruminant models examining how stimulation of the nervous system can affect GLP-2 secretion specifically, it has been established that stimulation of the vagus nerve affects endocrine secretion, such as insulin (Adrian et al., 1983). In a calf, ingestion of milk via suckling is directed to the abomasum via the esophageal groove and bypasses the rumen. In comparison, when calves consume solid feed it is directed into the rumen where fermentation occurs, and the amount of fermentation within the rumen increases as solid feed intake increases. It is possible that, as calves age, presence of nutrients in the rumen act to mechanically stimulate the vagus nerve, and the addition of feed to the digestive tract via the milk meal, can act to cause a biphasic response in GLP-2 secretion not seen in an animal fed milk only.

Given the possibility for VFA to play a role in GLP-2 secretion, it is possible that development of the ruminant gastrointestinal tract is also associated with changes in mechanism for vagus nerve stimulation, resulting in biphasic secretion of GLP-2 at wk 7, which was not seen earlier in life. These findings are of particular interest and warrant further investigation into the factors associated with GLP-2 secretion and clearance in calves as they age through the preweaning period.

Overall, the current study provides evidence that the amount of milk fed preweaning can alter GLP-2 secretion in dairy calves. Studies evaluating the relationship between nutrient intake, gastrointestinal development, and GLP-2 concentrations have been conducted in piglets with extensive sample analysis (Burrin et al., 2000) and support the link between increased GLP-2 concentrations in plasma and in increase in gastrointestinal development (Burrin et al., 2001). However, it is not possible to determine whether these changes in GLP-2 concentrations translate to changes in development of the gastrointestinal tract in the current study; therefore, investigation into the effects of GLP-2 concentrations in calves throughout the preweaning period on the gastrointestinal tract is warranted.

\section{CONCLUSIONS}

Feeding a high amount of milk preweaning tended to increase baseline GLP-2 concentrations and increased periprandial AUC. Plasma concentrations of GLP-2 decreased with age, and we noted an apparent adaptation for calves to exhibit a biphasic response in GLP2 to a milk meal. These mechanisms warrant further investigation.

\section{REFERENCES}

Adrian, T. E., S. R. Bloom, and A. V. Edwards. 1983. Neuroendocrine responses to stimulation of the vagus nerves in bursts in conscious calves. J. Physiol. 344:25-35.

Ash, R. W. 1959. Inhibition and excitation of reticulo-rumen contractions following the introduction of acids into the rumen and abomasum. J. Physiol. 147:58-73.

Brubaker, P. L., and Y. Anini. 2003. Direct and indirect mechanisms regulating secretion of glucagon-like peptide-1 and glucagon-like peptide-2. Can. J. Physiol. Pharmacol. 81:1005-1012.

Burgstaller, J., T. Wittek, and G. W. Smith. 2017. Invited review: Abomasal emptying in calves and its potential influence on gastrointestinal disease. J. Dairy Sci. 100:17-35.

Burrin, D., X. Guan, B. Stoll, Y. M. Petersen, and P. T. Sangild. 2003b. Glucagon-like peptide 2: A key link between nutrition and intestinal adaptation in neonates? J. Nutr. 133:3712-3716.

Burrin, D. G., Y. Petersen, B. Stoll, and P. Sangild. 2001. Glucagonlike peptide 2: A nutrient- responsive gut growth factor. J. Nutr. 131:709-712.

Burrin, D. G., B. Stoll, and X. Guan. 2003a. Glucagon-like peptide-2 function in domestic animals. Domest. Anim. Endocrinol. 24:103122.

Burrin, D. G., B. Stoll, R. Jiang, X. Chang, B. Hartmann, J. J. Holst, G. H. Greeley, and P. J. Reeds. 2000. Minimal enteral nutrient requirements for intestinal growth in neonatal piglets: How much is enough? Am. J. Clin. Nutr. 71:1603-1610.

Castro, J. J., S. Y. Morrison, A. Hosseinni, J. J. Loor, J. K. Drackley, and I. R. Ipharraguirre. 2016. Secretion of glucagon-like peptide-2 responds to nutrient intake but not glucose provision in milk-fed calves. J. Dairy Sci. 99:5793-5807.

Connor, E. E., S. Kahl, T. H. Elasser, R. L. Baldwin, R. Fayer, M Santin-Duran, G. L. Sample, and C. M. Evock-Clover. 2013. Glucagon-like peptide 2 therapy reduces negative effects of diarrhea on calf gut. J. Dairy Sci. 96:1793-1802.

Croom, W. J., L. S. Bull, and I. L. Taylor. 1992. Regulation of pancreatic exocrine secretion in ruminants: A review. J. Nutr. 122:191202.

de Jong, A. 1982. Patterns of plasma concentrations of insulin and glucagon after intravascular and intraruminal administration of volatile fatty acids in the goat. J. Endocrinol. 92:357-370.

Elsabagh, M., Y. Inabu, T. Sugino, and T. Obitsu. 2017. Response of plasma glucagon-like peptide-2 to feeding pattern and intraruminal administration of volatile fatty acids in sheep. Domest. Anim. Endocrinol. 60:31-41.

Gorka, P., Z. M. Kowalski, P. Pietrazak, A. Kotunia, R. Kiljanczyk, J. Flaga, J. J. Holst, P. Guillotear, and R. Zabielski. 2009. Effect of sodium butyrate supplementation in milk replacer and starter diet on rumen development in calves. J. Physiol. Pharmacol. 60:47-53.

Inabu, Y., A. Saegusa, K. Inouchi, S. Koike, M. Oba, and T. Sugino. 2017. Plasma concentrations of glucagon-like peptide 1 and 2 in calves fed starters containing lactose. J. Dairy Sci. 100:9361-9371.

Janssen, P., A. Rotondo, F. Mule, and J. Tack. 2013. Review article: a comparison of glucagon- like peptides. Aliment. Pharmacol. Ther. 37:18-36.

Kato, Y., D. Yu, and M. Z. Schwartz. 1999. Glucagonlike peptide-2 enhances small intestinal absorptive function and mucosal mass in vivo. J. Pediatr. Surg. 34:18-20. 
Khan, M. A., A. Bach, D. M. Weary, and M. A. G. von Keyserlink. 2016. Invited review: Transitioning from milk to solid feed in dairy heifers. J. Dairy Sci. 99:885-902.

Kvidera, S. K., E. A. Horst, M. V. Sanz Fernandez, M. Abuajamieh, S. Ganesan, P. J. Gorden, H. B. Green, K. M. Schoenberg, W. E. Trout, A. K. Keating, and L. H. Baumgard. 2017. Characterizing effects of feed restriction and glucagon-like peptide 2 administration on biomarkers of inflammation and intestinal morphology. J. Dairy Sci. 100:9402-9417.

Matsunaga, N., N. T. Arakawa, T. Goka, K. T. Nam, A. Ohneda, Y. Sasaki, and K. Katoh. 1999. Effects of ruminal infusion of volatile fatty acids on plasma concentration of growth hormone and insulin in sheep. Domest. Anim. Endocrinol. 17:17-27.

NRC. 2001. Nutrient Requirements of Dairy Cattle. 7th ed. Natl. Acad. Press, Washington, DC.

Palmquist, D. L., J. Doppenberg, K. L. Roehrig, and D. J. Kinsey. 1992. Glucose and insulin metabolism in ruminating and veal calves fed high and low fat diets. Domest. Anim. Endocrinol. 9:233-241.

Parodi, P. W. 1997. Cows' milk fat components as potential anticarcinogenic agents. J. Nutr. 127:1055-1060.

Petersen, Y. M., D. G. Burrin, and P. T. Sanglid. 2001. GLP-2 has differential effects on small intestine growth and function in fetal and neonatal pigs. Am. J. Physiol. Regul. Integr. Comp. Physiol. 281:R1986-1993.

Petersen, Y. M., B. Hartmann, J. J. Holst, I. Le Huerou-Luron, C. R. Bjornvad, and P. T. Sanglid. 2003. Introduction of enteral food increases plasma GLP-2 and decreased GLP-2 receptor mRNA abundance during pig development. J. Nutr. 133:1781-1786.

Rocca, A. S., and P. L. Brubaker. 1999. Role of the vagus nerve in mediating proximal nutrient- induced glucagon-like peptide-1 secretion. Endocrinology 140:1687-1694.

Rowland, K. J., and P. L. Brubaker. 2011. The "cryptic" mechanism of action of glucagon-like peptide-2. Am. J. Physiol. Gastrointest. Liver Physiol. 301:G1-8.

Sugino, T., Y. Hasegawa, Y. Kurose, M. Kojima, K. Kangawa, and Y. Terashima. 2004. Effects of ghrelin on food intake and neuroendocrine function in sheep. Anim. Reprod. Sci. 82-83:183-194.

Taylor-Edwards, C. C., D. G. Burrin, J. J. Holst, K. R. McLeod, and D. L. Harmon. 2011. Glucagon-like peptide-2 (GLP-2) increases small intestinal blood flow and mucosal growth in ruminating calves. J. Dairy Sci. 94:888-898.

Taylor-Edwards, C. C., D. G. Burrin, J. C. Matthews, K. R. McLeod, J. J. Holst, and D. L. Harmon. 2010. Expression of mRNA for proglucagon and glucagon-like peptide-2 (GLP-2) receptor in the ruminant gastrointestinal tract and the influence of energy intake. Domest. Anim. Endocrinol. 39:181-193.

Xiao, Q., R. P. Boushey, D. J. Drucker, and P. L. Brubaker. 2001 Secretion of the intestintropic hormone glucagon-like peptide 2 is differentially regulated by nutrients in humans. Gastroenterology 177:99-105. 